\title{
Stair Climbing in Young Boys: A Longitudinal Study
}

\section{Kathleen Williams, Lavon Williams, and H. Scott Strohmeyer}

\begin{abstract}
This longitudinal investigation examined the shift from use of a marking time to an alternating stepping pattern by young children. A set of twin males was videotaped between ages 37 and 46 months climbing stairs of $3.8-17.8 \mathrm{~cm}$ height. One boy began to alternate consistently on the highest steps at 41 months, the other at 46 months. Anthropometrics (leg lengths) and a measure of foot overshoot (maximum height of the foot over the stair) were used to investigate the timing of the shift for the 2 boys. Magnitude of overshoot decreased with age and with increased use of the more advanced pattern. Immature balance and an initial need to visually guide the foot to the next step may be important factors in the timing of the pattern shift.
\end{abstract}

The ontogenesis of walking has been extensively investigated $(2,5)$. There has been little systematic study, however, of developmental changes in walking in different contexts, such as stair climbing. McCaskill and Wellman (4) validated emergence and change of a variety of common motor tasks, including stair climbing. They reported a motor age of 24 months for climbing a "short" flight of stairs using a marking time pattern. Marking time is an action during which one foot meets the other on a riser, before going to the next higher (or lower) riser. Children used an alternating pattern by 31 months. By 41 months, they were able to climb a "long" flight without a hand hold. McCaskill and Wellman (4) did not analyze the form of motor patterns beyond general categories of marking time or alternating stepping patterns.

Ulrich et al. (6) investigated stair-climbing behaviors in children 8 to 25 months of age. They were interested in discovering what information infants and young children used to determine the "climbability" of stairs of different heights. For example, were steps climbable based on the relationship of riser height to body-scaled parameters, such as leg length? Ulrich et al. found young children's (8-18 months) choice of stairs was related to previous walking experience, as well as exposure to stairs. Children who had been walking longer or who had more experience tended to select stairs of medium height $(15.2 \mathrm{~cm})$. Children who were not yet walking chose shorter $(7.6 \mathrm{~cm})$ stairs. Older children (18-25 months) also viewed stairs as affording many other activities, beyond

Kathleen Williams and Lavon Williams are with the Department of Exercise and Sport Science at the University of North Carolina at Greensboro, Greensboro, NC 274125001. H. Scott Strohmeyer is with the Department of Physical Education at Central Missouri State University, Warrensburg, MO 64093. 
simple climbing. These children sometimes switched the stairs they climbed on or played on the stairs, rather than climbing directly to the top. Older subjects also used a variety of motor patterns to climb and descend stairs (e.g., crawling, turning).

Ulrich et al. (6) found no relation between body-scaled variables and young children's selection of a particular set of stairs. In contrast, Warren's study (7) of adult males resulted in a clear relationship between leg length and stair climbability. He found riser heights of $28 \%$ leg length were most efficiently climbed. Riser heights of $88 \%$ leg length were the maximum climbable height for adults. In an extension of that investigation, Konczak et al. (3) examined other variables for their importance to stair climbing by older (60-70 years) adults. Their results suggested leg strength and hip flexibility also made important contributions to an object's climbability.

These investigations $(3,4,6,7)$ examined subjects at different points of the lifespan for factors related to the ability to climb stairs of different heights. None of these investigations examined the form of the movement, however. Environmental constraints are likely to influence more than the simple ability to perform any action. For example, Warren (7) found that stairs of different relative riser heights resulted in actions that were more or less aerobically efficient. It is possible that differences in efficiency resulted in differences in movement pattern as well.

This longitudinal investigation of a set of twin male children extends earlier studies of stair "climbability" in that the form of the climb was studied, relative to shifting task constraints. Because the results of earlier research were mixed, we asked whether stair height relative to leg length would influence the specific climbing pattern used by young boys. Was there a relationship between relative stair height and use of marking time or alternating patterns? Because anthropometric measures were not consistently related to other aspects of stair climbing, the height of the foot's clearance of the stair was examined for its possible relationship to a shift from one stepping pattern to the other.

Identical twins were studied for two reasons. First, because a longitudinal, case-study approach was used, twins provided subjects with virtually identical anthropometric dimensions and experiences. Second, adherence to a monthly testing schedule was maximized. Finally, the longitudinal nature of this investigation enabled us to examine directly when changes in movement pattern occurred, relative to changes in task requirements.

\section{Methods}

\section{Subjects}

The subjects in this investigation were a set of identical twin males. They were 37 months old at the beginning of the investigation. Testing stopped when the boys were 46 months old. The children's parents read and signed an informed consent form before testing began.

\section{Testing Procedures}

Test Apparatus. Five sets of four stairs were used to test the participants. One was a "standard" set of stairs with risers that were $17.8 \mathrm{~cm}$ high. The other 
four sets of stairs had risers that were $3.8,7.6,11.4$, and $15.2 \mathrm{~cm}$ high. The influence of the riser height manipulation was the focus of this investigation, so tread depth was maintained at $27.9 \mathrm{~cm}$ for all stairs.

Test Procedures. Both boys were tested about once a month between June 1990 and March 1991. A total of eight testing sessions were held. When initially tested, neither child used an alternating stepping pattern when climbing the standard set of stairs. Both boys "marked time": Each foot contacted each stair before going to the next stair. Testing was ended in March of 1991, because both children consistently alternated steps (single and alternating contact with stairs) on the standard stairs.

Both boys were videotaped each month. Both were present during each testing session. In preparation, the children's clothing was removed and markers were applied to joint centers on the right side. Shoulder, hip, knee, ankle, heel, and metatarsophalangeal joints were marked. The children's father assisted at all testing sessions.

Testing always began using the standard set of stairs to determine whether either child had shifted from marking time to alternating stepping pattern. During sessions in which subjects were unable to alternate steps on the standard stairs, trials also were performed on the lower stairs, beginning with the $3.8 \mathrm{~cm}$ risers. An attempt was made to have each child complete at least five trials at each of the stair heights, from lowest to highest. Success in obtaining these trials varied with the cooperation of the children. Finally, selected anthropometric measures were made at each testing session. Thigh, shank, and total leg length measurements were made for the right side of the body.

\section{Experimental Measures}

Three types of measures were analyzed for this investigation. First, anthropometric measures of thigh, shank, and total leg were made using standard procedures. The first author measured each segment at least three times. These scores were averaged across the measurements. Measurement reliability was maintained at $\pm .2 \mathrm{~cm}$ at each testing session.

The pattern used to climb the stairs on each trial was recorded. The boys were classified using marking time, alternating, or mixed stepping patterns. A mixed pattern was a transition period when the children both alternated steps and marked time within a single trial.

Finally, an "overshoot" measure of the maximum height of the heel over a stair before touchdown was analyzed for the standard stairs. The $x$ and $y$ coordinates of each heel were digitized and converted to vertical distances (Peak Performance Systems, Englewood, CO). The point of maximum distance between heel and surface of each of the four stairs was located and the difference determined. Overshoots were analyzed using a $2 \times 8 \times 3 \times 2 \times 4 \times 2$ (Subject $\times$ Age $\times$ Trial $\times$ Foot $\times$ Stair $\times$ Step Type [marking time or alternating]) repeated measures ANOVA.

\section{Results}

A total of 400 trials was available for analysis for both boys. Child 1 performed 181 usable trials, and Child 2 performed 219 trials. 
Table 1 Leg Lengths and Relative Riser Heights Across Testing Periods

\begin{tabular}{|c|c|c|c|c|c|c|c|c|}
\hline \multirow[b]{2}{*}{$\begin{array}{c}\text { Age } \\
\text { (months) }\end{array}$} & \multicolumn{4}{|c|}{ Child 1} & \multicolumn{4}{|c|}{ Child 2} \\
\hline & $\begin{array}{l}\text { Thigh } \\
(\mathrm{cm})\end{array}$ & $\begin{array}{l}\text { Shank } \\
(\mathrm{cm})\end{array}$ & $\begin{array}{l}\text { Total } \\
\text { leg length } \\
(\mathrm{cm})\end{array}$ & $\begin{array}{l}\text { Rel. } \\
\text { height }\end{array}$ & $\begin{array}{l}\text { Thigh } \\
(\mathrm{cm})\end{array}$ & $\begin{array}{l}\text { Shank } \\
(\mathrm{cm})\end{array}$ & $\begin{array}{l}\text { Total } \\
\text { leg length } \\
(\mathrm{cm})\end{array}$ & $\begin{array}{c}\text { Rel. } \\
\text { height }\end{array}$ \\
\hline 37 & 17.7 & 18.6 & 41.2 & .43 & 17.6 & 18.7 & 41.2 & .43 \\
\hline 38 & \multicolumn{8}{|c|}{ No measurements at 38 months } \\
\hline 39 & 18.0 & 18.8 & 41.6 & .43 & 17.9 & 19.0 & 41.9 & .42 \\
\hline 40 & 18.6 & 19.3 & 41.7 & .43 & 18.3 & 19.4 & 41.9 & .42 \\
\hline 41 & 18.8 & 19.8 & 42.4 & .42 & 19.5 & 20.2 & 42.6 & .42 \\
\hline 43 & 19.0 & 19.8 & 42.8 & .42 & 19.5 & 20.3 & 42.6 & .42 \\
\hline 44 & 19.1 & 20.1 & 43.1 & .41 & 19.5 & 20.1 & 43.5 & .41 \\
\hline 46 & 19.1 & 20.4 & 43.9 & .40 & 19.5 & 20.2 & 43.8 & .41 \\
\hline
\end{tabular}

Note. Rel. height is height of the standard riser relative to total leg length.

\section{Anthropometric Measures}

Total leg length increases for each boy were less than $3 \mathrm{~cm}$ over the testing period. Thigh and shank changes ranged from 1.4 to $1.9 \mathrm{~cm}$ over that same period (Table 1). Throughout testing, thigh, shank, and total leg lengths were virtually identical for the two boys.

Stair height for the standard stairs relative to leg length was computed for each child. These heights ranged from .43 leg length for both boys at 37 months, to .40 and .41 leg length at 46 months (Table 1). There were no differences between the boys for any relative proportions.

\section{Stair Climbing Pattern}

At the beginning of testing (37 months) both boys used a marking-time pattern on all trials to climb the standard $(17.8 \mathrm{~cm})$ stairs (Table 2). Child 1 alternated steps on all trials, on all other stairs $(3.8-15.2 \mathrm{~cm})$. Child 2 used a marking-time pattern on all trials for all stairs except the lowest $(3.8 \mathrm{~cm})$ risers, for which he used an alternating pattern. A nearly identical pattern of performance was seen at 38 months. The only differences were that Child 1 used a "playful,", mixed pattern for one trial on the $15.2 \mathrm{~cm}$ stairs; Child 2 used the mixed pattern on the 7.6 and $11.4 \mathrm{~cm}$ stairs. He also alternated steps on half of his trials on the $7.6 \mathrm{~cm}$ stairs.

At 39 months, Child 1 began to use a mixed stepping pattern on the standard stairs. He continued to mark time on $55 \%$ of trials, while he mixed the patterns on the remaining $45 \%$ of his attempts. At this age, Child 2 performed much as he had at 38 months, sometimes mixing patterns on the lower stairs.

No major changes in stepping pattern were noted for either child at 40 months. During that test session, Child 1 demonstrated greater pattern variability 
Table 2 Percentage of Trials Categorized by Stepping Pattern

\begin{tabular}{|c|c|c|c|c|c|c|c|c|c|c|}
\hline Age & $\begin{array}{c}\text { Riser } \\
\text { height } \\
3.8\end{array}$ & $\begin{array}{l}\text { No. } \\
\text { trials }\end{array}$ & $\begin{array}{c}\text { Riser } \\
\text { height } \\
7.6\end{array}$ & $\begin{array}{l}\text { No. } \\
\text { trials }\end{array}$ & $\begin{array}{c}\text { Riser } \\
\text { height } \\
11.4\end{array}$ & $\begin{array}{l}\text { No. } \\
\text { trials }\end{array}$ & $\begin{array}{c}\text { Riser } \\
\text { height } \\
15.2\end{array}$ & $\begin{array}{l}\text { No. } \\
\text { trials }\end{array}$ & $\begin{array}{c}\text { Riser } \\
\text { height } \\
17.8\end{array}$ & $\begin{array}{l}\text { No. } \\
\text { trials }\end{array}$ \\
\hline \multicolumn{11}{|c|}{ Child 1} \\
\hline 37 & A 100 & 5 & A 100 & 5 & A 100 & 5 & A 100 & 5 & M 100 & 4 \\
\hline 38 & A 100 & 5 & A 100 & 5 & A 100 & 5 & $\begin{array}{l}\text { MX } 20 \\
\text { A } 80\end{array}$ & 5 & M 100 & 6 \\
\hline 39 & A 100 & 4 & A 100 & 4 & $\begin{array}{l}\text { MX } 17 \\
\text { A } 83\end{array}$ & 6 & A 100 & 4 & $\begin{array}{l}\text { M } 55 \\
\text { MX 45 }\end{array}$ & 11 \\
\hline 40 & $\begin{array}{l}\text { M } 20 \\
\text { A } 80\end{array}$ & 5 & $\begin{array}{l}\text { MX } 20 \\
\text { A } 80\end{array}$ & 5 & $\begin{array}{l}\text { M } 22 \\
\text { MX } 78\end{array}$ & 9 & $\begin{array}{l}\text { M } 78 \\
\text { MX } 11 \\
\text { A } 11\end{array}$ & 9 & M 100 & 5 \\
\hline 41 & A 100 & 4 & A 100 & 5 & A 100 & 6 & A 100 & 4 & $\begin{array}{l}\text { MX } 11 \\
\text { A } 89\end{array}$ & 9 \\
\hline 43 & A 100 & 3 & $\begin{array}{l}\text { M } 20 \\
\text { A } 80\end{array}$ & 5 & A 100 & 4 & A 100 & 7 & A 100 & 3 \\
\hline 44 & A 100 & 3 & N/A & 0 & A 100 & 4 & A 100 & 3 & $\begin{array}{l}\text { M } 80 \\
\text { MX } 20\end{array}$ & 5 \\
\hline 46 & N/A & 0 & N/A & 0 & N/A & 0 & N/A & 0 & A 100 & 5 \\
\hline
\end{tabular}

Child 2

\begin{tabular}{|c|c|c|c|c|c|c|c|c|c|}
\hline 37 & A 100 & 5 & M 100 & 5 & M 100 & 5 & M 100 & 5 & M 100 \\
\hline 38 & M 100 & 5 & $\begin{array}{l}\text { M } 30 \\
\text { MX } 20 \\
\text { A } 50\end{array}$ & 10 & $\begin{array}{l}\text { M } 57 \\
\text { MX } 43\end{array}$ & 7 & M 100 & 2 & M 100 \\
\hline 39 & $\begin{array}{l}\text { M } 50 \\
\text { MX } 50\end{array}$ & 14 & $\begin{array}{l}\text { M } 80 \\
\text { MX } 20\end{array}$ & 5 & M 100 & 3 & M 100 & 4 & M 100 \\
\hline 40 & $\begin{array}{l}\text { MX } 50 \\
\text { A } 50\end{array}$ & 4 & A 100 & 2 & $\begin{array}{l}\text { M } 57 \\
\text { MX } 43\end{array}$ & 7 & M 100 & 6 & M 100 \\
\hline 41 & $\begin{array}{l}\text { MX } 25 \\
\text { A } 75\end{array}$ & 4 & $\begin{array}{l}\text { MX } 40 \\
\text { A } 60\end{array}$ & 5 & $\begin{array}{l}\text { MX } 40 \\
\text { A } 60\end{array}$ & 5 & $\begin{array}{l}\text { MX } 25 \\
\text { A } 75\end{array}$ & 4 & M 100 \\
\hline 43 & A 100 & 3 & A 100 & 3 & A 100 & 3 & $\begin{array}{l}\text { M } 13 \\
\text { MX } 53 \\
\text { A } 33\end{array}$ & 15 & $\begin{array}{l}\text { M } 78 \\
\text { MX } 22\end{array}$ \\
\hline 44 & $\begin{array}{l}\text { MX } 25 \\
\text { A } 75\end{array}$ & 4 & $\begin{array}{l}\text { M } 71 \\
\text { MX } 29\end{array}$ & 7 & $\begin{array}{l}\text { M } 60 \\
\text { MX } 10 \\
\text { A } 30\end{array}$ & 10 & $\begin{array}{l}\text { M } 83 \\
\text { MX } 17\end{array}$ & 6 & $\begin{array}{l}\text { M } 88 \\
\text { MX } 12\end{array}$ \\
\hline 46 & N/A & 0 & N/A & 0 & N/A & 0 & N/A & 0 & $\begin{array}{l}\text { M } 55 \\
\text { MX } 18 \\
\text { A } 27\end{array}$ \\
\hline 46 & N/A & 0 & N/A & 0 & N/A & 0 & N/A & 0 & A 100 \\
\hline
\end{tabular}

Note. $\mathrm{A}=$ percentage use of an alternating stepping pattern. $\mathrm{M}=$ percentage use of a marking time pattern. $\mathrm{MX}=$ percentage use of a mixed (marking time and alternating) pattern. 
at several stair heights. Examination of trials suggested he was "playing" rather than performing his best. That is, despite cues and encouragement from the experimenter and his father, Child 1 sometimes marched and sometimes tip-toed up the stairs. At 41 months, Child 1 shifted to an alternating stepping pattern on the standard steps $89 \%$ of the time. He continued to use a consistent alternating pattern on the lower stairs as well. Child 2 used either alternating or mixed stepping on all the lower stairs. He continued to use only a marking-time pattern on the standard stairs, however.

For the remaining 3 months of the investigation (43-46 months), Child 1 continued to alternate steps consistently at all stair heights. There were a couple of trials at 43 and 44 months during which a marking time or mixed pattern was used on some steps. This shift to a less mature pattern again was tied to a playfulness rather than any real regression. In contrast, over these 4 months, Child 2 shifted more completely toward using mixed or alternating patterns on all stairs, including the standard ones. At 43 months, he alternated consistently on stairs between 3.8 and $11.4 \mathrm{~cm}$. At $15.2 \mathrm{~cm}$, he used all three patterns: $13 \%$ marking time ( 2 trials), 53\% mixed ( 8 trials), and 33\% alternating (5 trials). On the standard stairs, he marked time $78 \%$ of the time ( 7 trials) and used a mixed pattern on the remaining $22 \%$ of trials (2). A similar pattern was seen at 44 months.

At the final testing session at 46 months, Child 2 shifted to an alternating pattern on the standard stairs. This session consisted of two parts. During the first part of testing, he used each of the three patterns. A rest period was given while Child 1 was tested. During the second half, he used only the alternating pattern ( 7 trials).

\section{Foot Overshoot}

During testing, it became clear that anthropometric differences between the boys would not account for differences in the stepping patterns they used. Anthropometric measures and reports of the children's experiences were virtually identical, yet there was a 5-month lag in the age each began to alternate steps. Another measure was sought to determine why the shift from marking time to alternating differed for the two boys. Amount of foot overshoot was selected as a possible candidate. It was hypothesized children might alter this height over the stairs as they shifted from one pattern to the other.

Significant main effects occurred for age $F(7,135)=2.62, p=.014$, foot (lead vs. trail), $F(1,135)=15.57, p<.01$, and step type, $F(1,135)=7.21, p<$ .01 . Mixed pattern trials were not included in this analysis. No interactions were significant. Post hoc Scheffé tests of the age main effect (Figure 1) demonstrated the overshoot at 40 months was greater than at either 41 or 43 months. Although no other significant age-related differences occurred, differences between 39 and 40 months and 40 and 46 months approached significance. Overall, although not statistically reliable, there was a tendency for overshoot to decline over the course of the investigation. In particular, the amount of overshoot that occurred during the final 4 months of the study was less than that observed in the first 4 months.

The trail leg consistently overshot the step more than the lead leg (Figure 2). The size of trail leg overshoot was nearly $50 \%$ greater than that of the lead leg. Overshoot for the two stepping patterns also differed. Overshooting was 


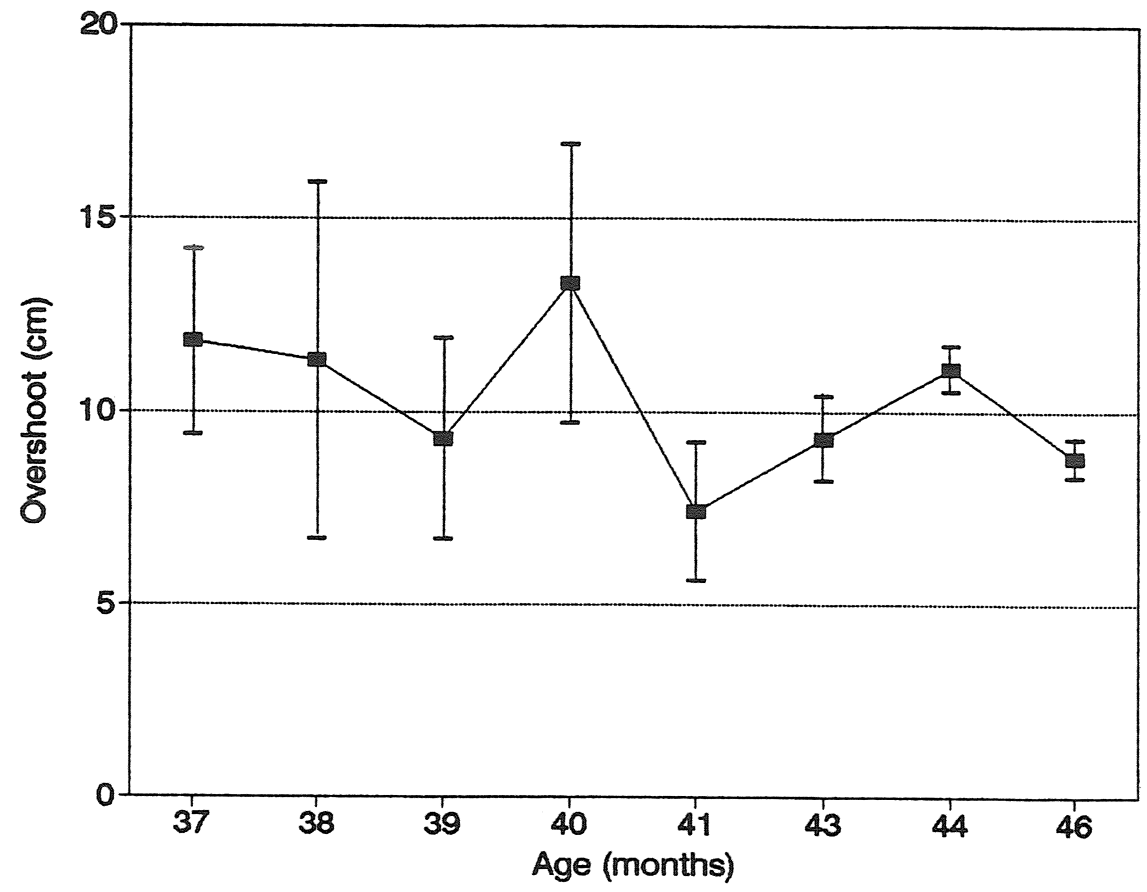

Figure 1 - Mean overshoot of foot for monthly test sessions ( \pm 1 standard deviation is also shown).

greater when the children marked time than when they alternated steps (Figure 3 ). In general, these results suggested that as the children grew older, the size of their overshoot declined. This decline was consistent with greater use of alternating steps.

\section{Discussion}

The aim of this investigation was to examine parameters related to a shift in stair climbing pattern from marking time to alternating steps. First, we examined stair riser height as it related to leg length. Previous research with adults $(3,7)$ resulted in finding that relative riser height was important for selecting which stairs to climb or for affording the most efficient form of climbing. It was less clear whether body-scaled parameters were important for determining how young children climbed stairs (6). Additionally, the type of movement pattern used by subjects was not a primary focus of any investigation.

As anticipated, anthropometric measures were virtually identical for both boys throughout the study. Total leg lengths, relative to standard stair height (Table 1), were greater than the .28 ratio Warren (7) reported for optimal riser height, but far less than the .88 ratio he reported for a maximally climbable riser. When leg lengths were compared to the lower stairs, ratios ranged from .09 


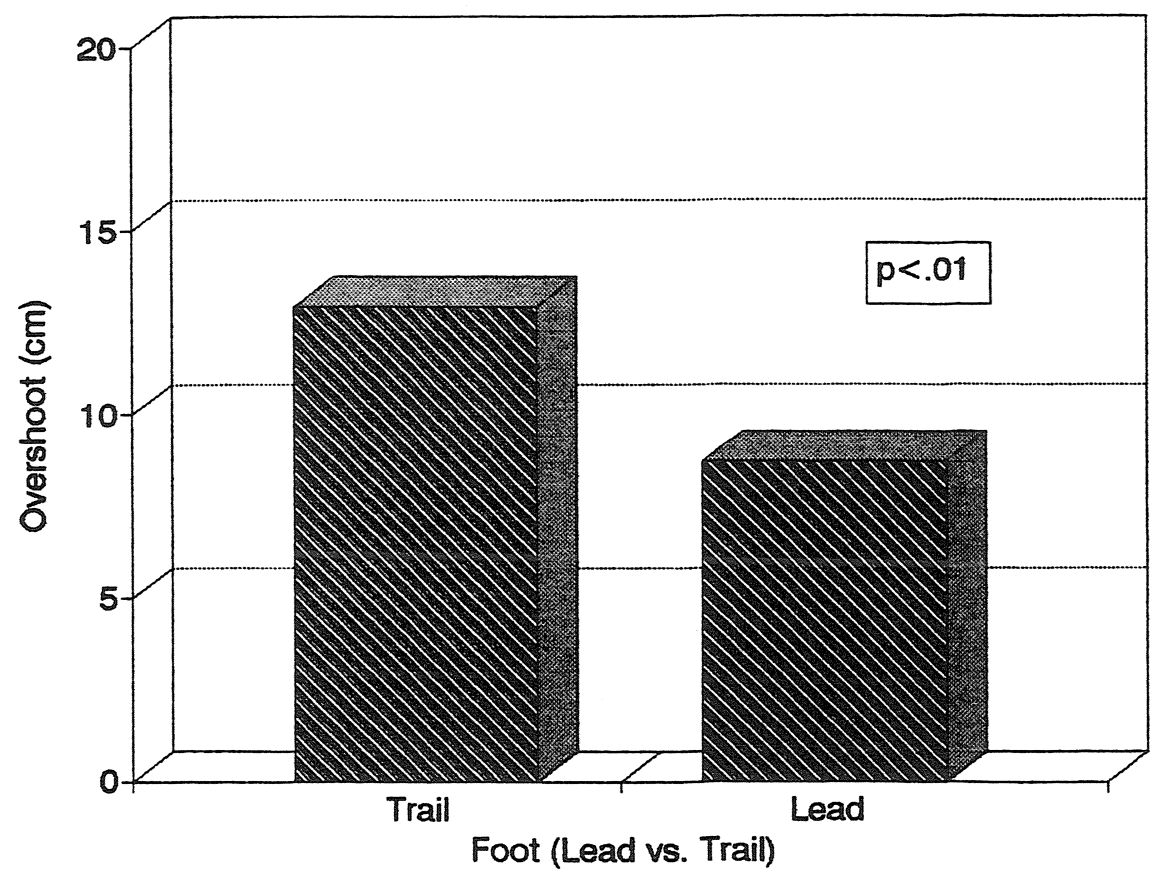

Figure 2 - Mean overshoot for lead and trail legs.

(3.8 $\mathrm{cm}$ stair) to $.36(15.2 \mathrm{~cm}$ stair). All of these ratios are considerably smaller than the .88 ratio reported for stairs that were maximally climbable (7). Because the onset of use of the alternating pattern occurred at such disparate times for the 2 boys (except on the $3.8 \mathrm{~cm}$ stairs), leg length was unlikely to be a critical factor in the shift from one pattern to the other. Our results are consistent with Ulrich et al.'s (6) finding that anthropometric measures were unrelated to the use of certain stairs by infants and young children.

Ulrich et al. (6) did find experience to be related to selection of certain stairs. No formal measures of experience were obtained for the twins in this investigation. The boys played together constantly, however, and shared nearly identical interests. Both often interacted with stairs. They sometimes accompanied their father to work, which required them to climb several long flights of stairs. They also negotiated stairs daily at home. Different experiences by the boys also were unlikely to make a strong contribution to pattern differences identified in this investigation.

Subjects in this study demonstrated less advanced behavior in their stair climbing than reported by McCaskill and Wellman (4). They reported a motor age of 31 months for using an alternating pattern on a short flight of stairs, similar to the standard stairs in this study. In contrast, the boys in this investigation did not consistently alternate steps until either 41 or 46 months. It is unclear how McCaskill and Wellman (4) assigned scores to children's performances, 


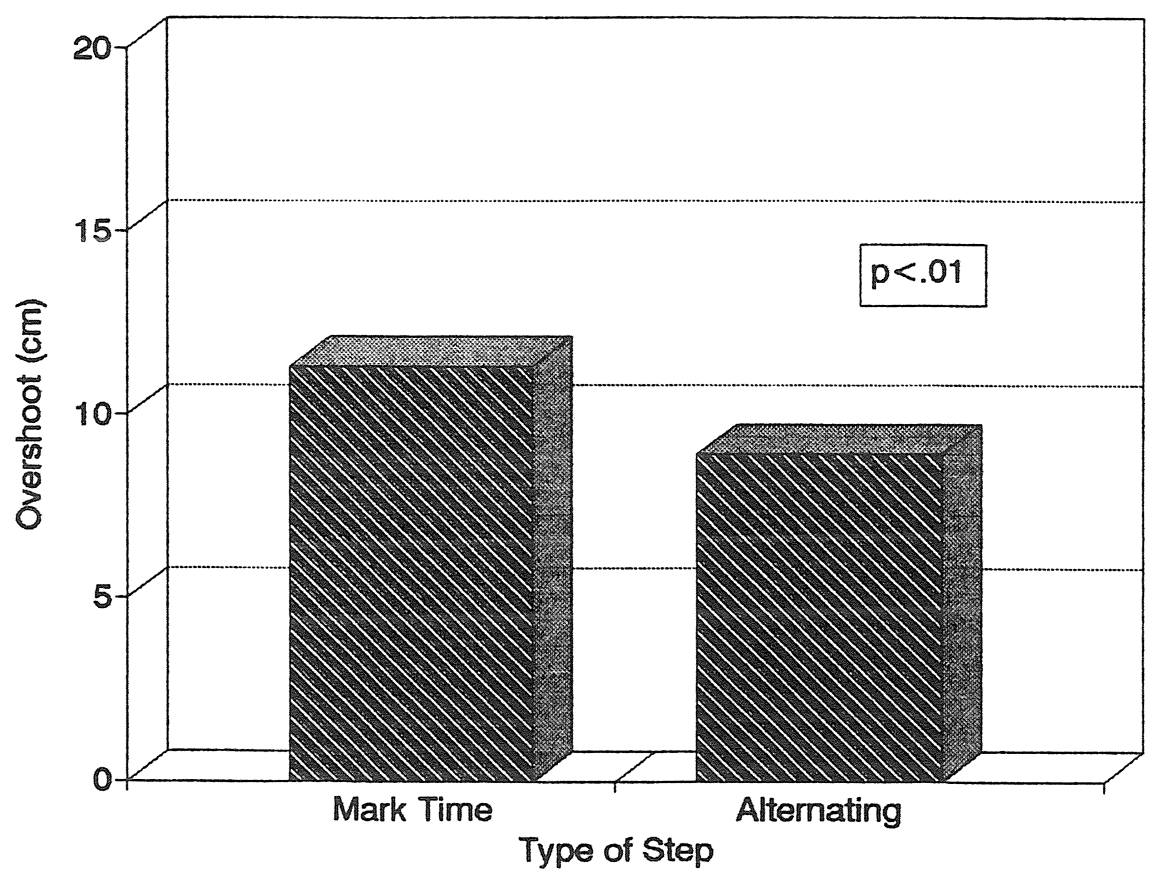

Figure 3 - Mean overshoot for type of stepping (marking time vs. alternating steps).

however. Using an alternating step in any part of a trial may have been scored as an alternating pattern. We classified that response as a mixed pattern.

Differences in the clearance of the feet during stepping may give some clues about the transition from marking time to an alternating stepping pattern. Both boys overshot less when they used an alternating pattern. There was also a general tendency toward less overshoot with age. These findings suggest a relationship between use of an alternating pattern and a more efficient movement pattern (i.e., one in which the foot is brought up only high enough to clear the nosing of the stair).

The specific cause of the pattern shift cannot be ascertained from this investigation. It is impossible to determine if lessening the height of the stepping motion resulted from or encouraged use of the alternating pattern. A shift to the alternating pattern may "force" a decrease in distance between foot and step in order to maintain balance. The foot might be kept closer to the stair when using an alternating pattern, since the moving foot is brought from two stairs away, rather than from the adjacent stair (as in marking time). The greater distance traversed during the alternating action could result in a larger perturbation to balance, particularly for a small child. Therefore, shifting to an alternating pattern may result in less overshoot and maximize stability.

Why might young subjects overshoot more when they mark time? Archea (1) found that adults descending stairs used visual and kinesthetic information 
for transition from floor to stairs. With less experience and limited visibility of the trail foot, young subjects may use a similar process. Use of more overshoot may allow inexperienced climbers a "peek" at their foot, as well as afford greater clearance and safety in reaching a stair. Additionally, Konczak et al. (3) suggested older adults were more cautious in their predictions of what was climbable because of their concerns with safety. Young children are likely to have similar safety concerns.

Balance competency might constrain how high the foot can go when alternating steps. Greater overshoot could perturb balance. Our results demonstrated that the boys overshot more with their trail leg than their lead leg, consistent with the scenario described above. It is more likely that safety concerns, coupled with tenuousness in balance result in use of the marking time pattern.

A closer examination of the stepping patterns used by the boys with the specific amount of their overshoot suggests that the scenario outlined above is plausible. While the amount of overshoot declined as the children got older, there were two sessions in which this general trend was reversed: at 40 months and again at 44 months (Figure 1). In each case, these were times that preceded or included major pattern shifts. For example, although Child 1 used only the marking time pattern to climb the standard stairs at 40 months, he demonstrated high variability in the pattern used on the lower stairs. The following month, he shifted to an alternating pattern on $89 \%$ of his trials on the standard stairs. At 44 months, Child 2 was highly variable in the patterns he used at all stair heights. He also used the mixed pattern on more trials. At 46 months, he shifted nearly exclusively to the alternating pattern. These patterns of change suggest that overshoot increases just before a shift in movement pattern. However, longitudinal study with many more subjects is necessary to test this hypothesis.

This investigation was an examination of longitudinal changes in stepping patterns used by young children to climb stairs. We were unable to uncover precise information about causes for the shift from marking time to alternating stepping. However, we supported earlier findings $(3,6)$ that anthropometric measures were insufficient to explain changes in stair climbing. Additional, longitudinal research with larger groups of children is necessary to determine the role of balance and other factors in the shift from one movement pattern to another.

\section{References}

1. Archea, J. Environmental factors associated with stair accidents by the elderly. In: Clinics in Geriatric Medicine, T.S. Radebaugh, E. Hadley, and R. Suzman (Eds.). Philadelphia: Saunders, 1985, pp. 555-570.

2. Clark, J.E., J. Whitall, and S.J. Phillips. Human interlimb coordination: The first 6 months of independent walking. Dev. Psychobiol. 21:445-456, 1988.

3. Konczak, J., H.J. Meeuwson, and M.E. Cress. Changing affordances in stair climbing: The perception of maximum climbability in young and older adults. J. Exp. Psych. Human Per. and Perform. 18:691-697, 1992.

4. McCaskill, C., and B. Wellman. A study of common motor achievements at the preschool ages. Cog. Dev. 9:141-150, 1938.

5. Thelen, E., B.D. Ulrich, and J.L. Jensen. The developmental origins of locomotion. In: The Development of Posture and Gait Across the Lifespan, M. Woollacott and A. 
Shumway-Cook (Eds.). Columbia: University of South Carolina Press, 1989, pp. 2547.

6. Ulrich, B.D., E. Thelen, and D. Niles. Perceptual determinants of action: Stair-climbing choices of infants and toddlers. In: Advances in Motor Development Research (Vol. 3), J. Clark and J. Humphrey (Eds.). New York: AMS Press, 1990, pp. 1-15.

7. Warren, W.H. Perceiving affordances: Visual guidance of stair climbing. J. Exp. Psych. Human Per. and Perform. 10:683-703, 1984.

\section{Acknowledgments}

We would like to thank Dr. Martie Skinner for her assistance in statistical analysis of the data. We thank two anonymous reviewers for their insightful comments. 